\title{
Perbandingan Kualitas Hasil Pengecoran Metode Sand Casting Dan Metode Pengembangan Lost Foam Invesment Casting Dengan Variasi Bahan Pengikat Berdasarkan Analisis Hasil Pengecoran
}

\author{
Anan Tri Asmoro ${ }^{1}$, Putut Murdanto ${ }^{2}$, Duwi Leksono Edy ${ }^{3}$ \\ 1,2,3Program Studi S1 Pendidikan Teknik Mesin Jurusan Teknik Mesin \\ ${ }^{1,2,3}$ Fakultas Teknik Universitas Negeri Malang \\ 1,2,3 Jalan Semarang No. 5, Malang 65145 \\ Email: anantriasmoro@gmail.com
}

\begin{abstract}
Abstrak. Penelitian ini merupakan penelitian komparasi antara metode sand casting dan pengembangan metode lost foam investment casting dengan variasi bahan pengikat bentonit pada sand casting dan semen merah pada lost foam investment casting. Metode yang digunakan pada penelitian ini menggunakan metode pre experimental design dengan model intact group comparision dengan analisis deskriptif. Pengujian yang digunakan meliputi uji visual, uji kekersan vikers, dan struktur mikro. Adapun hasil dari penelitian ini menunjukkan pada uji visual didapatkan metode pengembangan lost foam investment casting memiliki kehalusan yang lebih baik dari sand casting. Berdasarkan nilai kekerasan vikers lost foam investment casting memiliki nilai kekerasan $61.07 \mathrm{HV}$ lebih tinggi dari sand casting dengan nilai kekerasan rata-rata 55.85 HV. Berdasarkan nilai uji struktur mikro didapatkan lost foam invesment casting memiliki struktur butir yang lebih homogeny dibandingkan dengan sand casting.
\end{abstract}

Kata Kunci: Kualitas, Sand casting, Lost foam invesment casting, Pengikat, Hasil Pengecoran.

\begin{abstract}
This research conducted descriptive comparison research between sand casting method with variation of bentonite and red cement on development of lost foam investment casting method. The method that use at this research is pre experimental design method with intact group comparision model and descriptive analysis. The research results as follow: Based on the result of visual test, lost foam investment casting method has smaller casting defect from sand casting method seen from comparison of casting roughness. Based on hardness test, it is obtained average of lost foam investment casting method is $61.07 \mathrm{HV}$ and sand casting method is $55.87 \mathrm{HV}$. Based on micro structure test, it is found that particle distribution for lost foam investment casting method has good distribution pattern with well and homogenous distributed silicates.
\end{abstract}

Keyword: Kualitas, Sand casting, Lost foam invesment casting, Binder, Casting Results.

Berdasarkan Badan Pusat Statistik (BPS) (2018) menyatakan pertumbuhan produksi manufaktur di Indonesia mengalami kenaikan signifikan. Pada Triwulan I-2018. Untuk industri manufaktur besar dan sedang naik sebesar 5.01 persen terhadap Triwulan I-2017. Industri pengecoran logam yang masuk kedalam industri logam dasar meningkat sebesar 9,92\%. Menurut Abdullah (2005) Perkembangan industri pengecoran logam tidak dapat dirasakan sebagian besar industri kecil menengah. Permasalahan dasarnya adalah ketergantungan bahan import pengadaan mesin dan harga yang biaya yang mahal.

Metode pengembangan lost foam invesment casting merupakan metode yang memadukan antara pengecoran konvensional dan modern terdiri dari konsep sand casting, lost foam casting, invesment casting dan die casting. Menggunakan pola foam sebagaimana lost foam casting cetakan yang terbuat dari tanah liat dan pasir sebagaimana sand casting cetakan yang dikeraskan sebagaimana die casting dan pola yang dihilangkan sebelum penuangan logam cair sebagaimana invesment casting.

Pada penelitian ini dilakukan penelitian eksperiment guna meneliti apakah pengecoran dengan metode pengembangan Lost Foam Invesment Casting menghasilkan kualitas hasil pengecoran yang lebih baik atau tidak. Metode yang digunakan guna mencari hubungan tersebut adalah dengan metode Pre-Eksperimental dengan model Intact-Group Comparison. akan dilakukan dua percobaan pengecoran. Pengecoran pertama dengan menggunakan metode Sand Casting yang kedua dengan metode pengembangan Lost foam Invesment Casting yang kemudian hasil dari pengecoran akan dianalisis cacat pengecorannya.

\section{METODE}

Metode penelitian merupakan upaya yang dilakukan oleh peneliti guna mendapatkan data dengan maksud tertentu berdasarkan kajian keilmuan melalui sebuah penelitian. Dalam penelitian menurut (Sugiyono, 2018:2) ada beberapa hal yang 
yang harus diperhatikan dalam kajian ilmiah yakni cara ilmiah, tujuan penelitian, dan kegunaan penelitian. Dalam penelitian ini metode yang digunakan adalah Metode Pre Eksperimental Design dengan model Intact-Group Comparison yang kemudian pada penelitian ini akan dibuat dua kelompok penelitian.

Pertama Sand Casting yang akan menjadi kelompok kontrol dan Pengembangan Lost Foam Invesment Casting sebagai kelompok eksperimen. Kelompok kontrol merupakan kelompok yang tanpa dilakukan eksperimen atau perlakuan, jadi variabel yang akan diteliti pada kelompok ini berdasarkan penelitian yang sudah ada pada sebelumya. Sedangkan kelompok eksperimen merupakan kelompok yang mendapatkan perlakuan dalam hal ini metode pengembangan Lost Foam Invesment Casting yang akan diteliti pengaruh terhadap kualitas hasil pengecoran.

Variabel penelitian merupakan suatu ketetapan yang ditetapkan oleh peneliti yang menjadi dasar untuk dipelajari dan diberi kesimpulan yang biasanya berupa suatu atribut atau sifat yang nilainya ditentukan peneliti (Sugiyono, 2010:38). Adapun variabel-variabel yang yang digtetapkan pada penelitian ini sebagai berikut:

1. Variabel Bebas (independent).

Variabel bebas (independent) merupakan variabel yang bebas ditentukan dan tidak terikat atau dipengaruhi oleh variabel lain:

Kelompok $\mathrm{O}_{1} \quad$ : Semen merah dengan persentase $(4 \%, 6 \%$, dan $8 \%)$.

Kelompok $\mathrm{O}_{2} \quad$ : Bentonit dengan persentase $(4 \%, 6 \%$,dan $8 \%)$.

2. Variabel Terikat (dependent).

Variabel terikat yaitu variabel yang nilainya tergantung oleh variable bebas adapun variasi ini meliputi: Uji Visual, Uji

Kekerasan, Uji Struktur Mikro.

3. Variabel Kontrol.

Merupakan variabel yang variasinya di pada peneliti. Variabel kontrol pada penelitian ini antara lain:
a. Kelompok $\mathrm{O}_{1}$
: Tanah liat, pasir, kadar air.
b. Kelompok $\mathrm{O}_{2}$
: Pasir silika, kadar air.
c. Logam yang digunakan dalam penelitian ini Aluminium Silikon (Al-Si) daur ulang.
d. Speseimen Uji dengan Ukuran sisi atas 50X50 mm yang diberi champer pada sisinya.
e. Temperatur penuangan $650^{\circ} \mathrm{C}$.
f. Lama Peleburan 30 menit.

Instrumen Penilaian Uji Kekerasan

\begin{tabular}{|c|c|c|c|c|c|}
\hline \multirow[t]{2}{*}{ Metode Pengecoran } & \multicolumn{3}{|c|}{ Titik Uji } & \multirow{2}{*}{$\begin{array}{l}\text { Rata-rata } \\
\text { spesimen }\end{array}$} & \multirow{2}{*}{$\begin{array}{c}\text { Rata-rata } \\
\text { Total }\end{array}$} \\
\hline & 1 & 2 & 3 & & \\
\hline \multicolumn{6}{|l|}{ Spesimen 1} \\
\hline Spesimen 2 & & & & & \\
\hline Spesimen 3 & & & & & \\
\hline
\end{tabular}

Instrumen Penilaian Uji Visual

\begin{tabular}{|c|c|c|}
\hline \multirow[t]{2}{*}{ No } & \multicolumn{2}{|c|}{ Metode Pengecoran } \\
\hline & Sand Casting & Lost foam invesment casting \\
\hline \multirow[t]{2}{*}{1} & & \multirow[b]{2}{*}{$\begin{array}{c}\text { Gambar Hasil Lost Foam IC } \\
\text { Variasi Semen Merah (\%) }\end{array}$} \\
\hline & $\begin{array}{c}\text { Gambar hasil Sand casting } \\
\text { Variasi Bentonit (\%) }\end{array}$ & \\
\hline
\end{tabular}

Instrumen Penilaian Uji Struktur Mikro

\begin{tabular}{|l|l|l|l|l|l|l|l|l|}
\hline \multicolumn{4}{|c|}{ Sand Casting Bentonit 4\% } & \multicolumn{3}{c|}{ Lost Foam Invement Casting Semen Merah 4\% } \\
\hline 1 & 2 & 3 & 4 & 5 & 1 & 2 & 3 & 4 \\
\hline & & & & & & & & \\
\end{tabular}




\section{Uji Visual}

\section{HASIL DAN PEMBAHASAN}

Secara visual dapat diketahui bahwa metode lost foam invesment casting memiliki kualitas hasil pengecoran yang lebih halus dibandingkan dengan sand casting.

Hasil Visual Pengecoran Sand casting dan Lost foam invesment casting

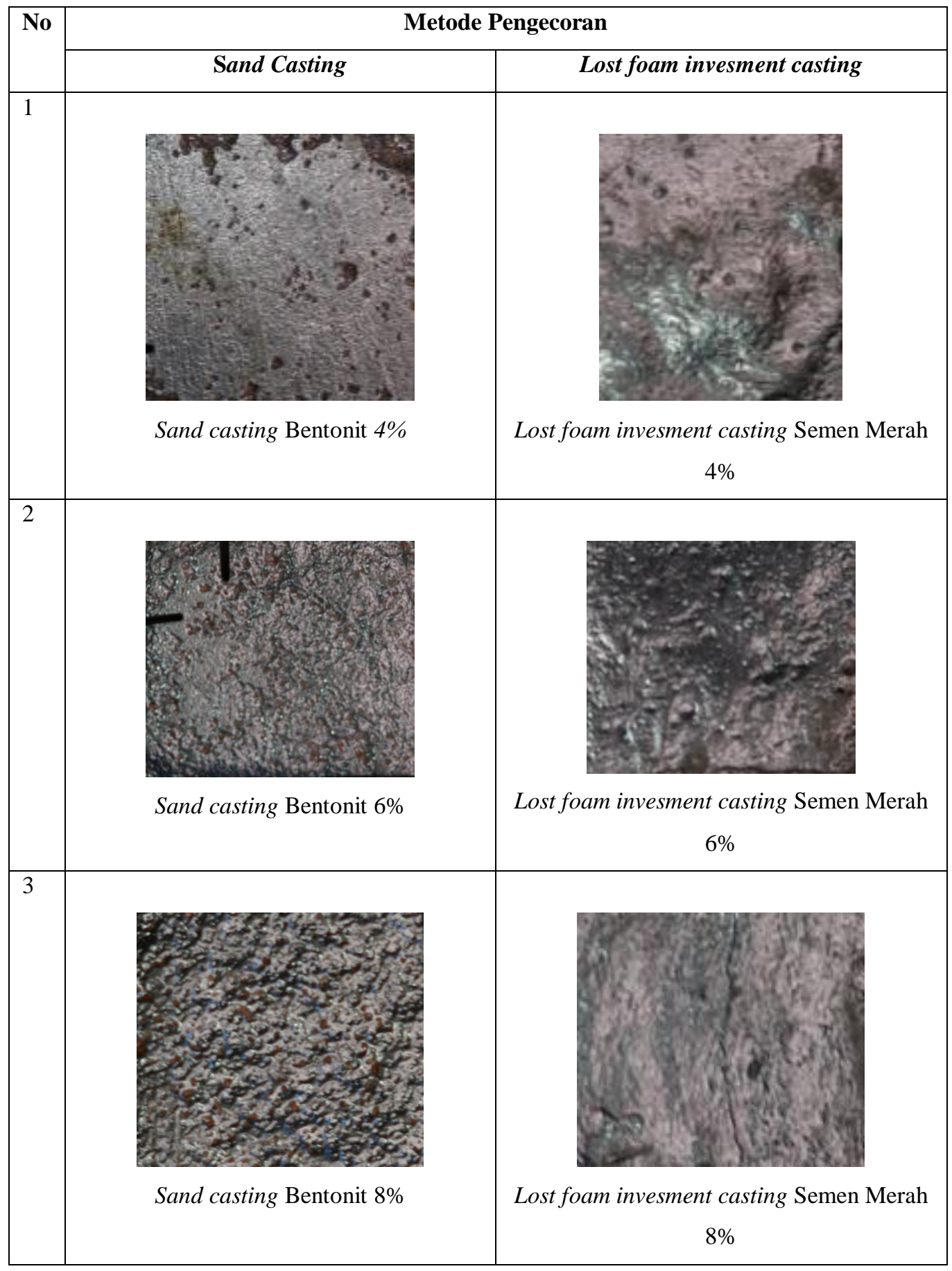

Menurut penelitian pengabdian (Suyitno, 2016:66) menerangkan bahwa pengecoran dengan cetakan permanen atau die casting memiliki hasil pengecoran yang lebih baik dari metode menggunakan pasir atau Sand Casting jika dilihat dari kualitas cacat coran. Salah satu metode yang diterapkan pada lost foam invesment casting adalah metode die casting sehingga dapat 
dibuktikan hasil pengecoran yang didapat dari die casting menghasilkan kualitas hasil pengecoran jika dilihat dari kekasaran permukaannya.

\section{Uji Kekerasan}

1. Sand casting Bentonit $4 \%$

Berdasarkan hasil pengujian kekerasan vickres (HV) Sand casting dengan variasi Bentonit 4\%, Pasir Silika 91\%, dan Air 5\% didapatkan data berikut:

Nilai Kekerasan (HV) Sand casting Variasi Bentonit 4\%

\begin{tabular}{cccccc}
\hline $\begin{array}{c}\text { Sand Casting } \\
\text { Variasi Bentonit 4\% }\end{array}$ & $\mathbf{1}$ & Titik Uji & & $\begin{array}{c}\text { Rata-rata } \\
\text { spesimen }\end{array}$ & $\begin{array}{c}\text { Rata-rata } \\
\text { Total }\end{array}$ \\
\cline { 1 - 4 } Spesimen 1 & 33,3 & $\mathbf{2}$ & $\mathbf{3}$ & 38,7 & \\
\cline { 1 - 4 } Spesimen 2 & 52,8 & 55 & 61,5 & 56,4 \\
\cline { 1 - 4 } Spesimen 3 & 41,7 & 52,4 & 63,9 & 52,7 & \\
\hline
\end{tabular}

2. Sand casting Bentonit $6 \%$

Berdasarkan hasil pengujian kekerasan vickres (HV) Sand casting dengan variasi Bentonit 6\%, Pasir Silika 89\%, dan Air 5\% didapatkan data berikut:

Nilai Kekerasan (HV) Sand casting Variasi Bentonit 6\%

\begin{tabular}{|c|c|c|c|c|c|}
\hline \multirow{2}{*}{$\begin{array}{c}\text { Sand Casting Variasi } \\
\text { Bentonit } 6 \%\end{array}$} & \multicolumn{3}{|c|}{ Titik Uji } & \multirow{2}{*}{$\begin{array}{l}\text { Rata-rata } \\
\text { spesimen }\end{array}$} & \multirow{2}{*}{$\begin{array}{c}\text { Rata-rata } \\
\text { Total }\end{array}$} \\
\hline & 1 & 2 & 3 & & \\
\hline Spesimen 1 & 64,9 & 58,6 & 62,4 & 61,9 & \multirow{3}{*}{59,4} \\
\hline Spesimen 2 & 49,9 & 59,1 & 63,9 & 57,6 & \\
\hline Spesimen 3 & 57,7 & 56,2 & 62,2 & 58,7 & \\
\hline
\end{tabular}

3. Sand casting Bentonit $8 \%$.

Berdasarkan hasil pengujian kekerasan vickres (HV) Sand casting dengan variasi Bentonit 8\%, Pasir Silika 87\%, dan Air 5\% diperoleh data seperti dibawah ini:

Nilai Kekerasan (HV) Sand casting Variasi Bentonit 8\%

\begin{tabular}{cccccc}
\hline $\begin{array}{c}\text { Sand Casting Variasi } \\
\text { Bentonit 8\% }\end{array}$ & $\mathbf{1}$ & Titik Uji & & $\begin{array}{c}\text { Rata-rata } \\
\text { spesimen }\end{array}$ & $\begin{array}{c}\text { Rata-rata } \\
\text { Total }\end{array}$ \\
\cline { 2 - 5 } Spesimen 1 & 59.7 & 57,4 & 61,9 & 59,7 & \\
\hline Spesimen 2 & 62,8 & 55,3 & 47,8 & 55,3 & \multirow{2}{*}{58,9} \\
\hline Spesimen 3 & 60 & 60,6 & 65 & 61,8 & \\
\hline
\end{tabular}

4. Lost foam invesment casting Semen Merah $4 \%$

Berdasarkan hasil pengujian kekerasan vickres (HV) Lost foam invesment casting dengan variasi Semen Merah 4\%, Tanah Liat $71 \%$, dan Air 25\% didapatkan data berikut:

Nilai Kekerasan (HV) Lost foam invesment casting Semen Merah $4 \%$

\begin{tabular}{cccccc}
\hline $\begin{array}{c}\text { Lost Foam Invesment } \\
\text { Semen Merah 4\% }\end{array}$ & $\mathbf{1}$ & Titik Uji & $\begin{array}{c}\text { Rata-rata } \\
\text { spesimen }\end{array}$ & $\begin{array}{c}\text { Rata-rata } \\
\text { Total }\end{array}$ \\
\cline { 1 - 5 } Spesimen 1 & 60,4 & 64 & 74,4 & 66,3 & \\
\cline { 1 - 4 } Spesimen 2 & 90,1 & 72,6 & 61,7 & 74,8 & \multirow{6}{*}{64,4} \\
\hline Spesimen 3 & 52,8 & 45,5 & 57,7 & 52 & \\
\hline
\end{tabular}

5. Lost foam invesment casting Semen Merah 6\%

Berdasarkan hasil pengujian kekerasan vickres (HV) Lost foam invesment casting dengan variasi Semen Merah 6\%,

Tanah Liat 69\%, dan Air 25\% didapatkan data berikut:

Nilai Kekerasan (HV) Lost foam invesment casting Variasi Semen Merah 6\%

\begin{tabular}{cccccc}
\hline $\begin{array}{c}\text { Lost Foam Invesment } \\
\text { Semen Merah 6\% }\end{array}$ & $\mathbf{1}$ & Titik Uji & Rata-rata & $\begin{array}{c}\text { Rata-rata } \\
\text { Spesimen }\end{array}$ & Total \\
\cline { 2 - 5 } Spesimen 1 & 61,1 & 59,3 & 62,9 & 61,1 & \\
\hline Spesimen 2 & 67,1 & 68,1 & 47,7 & 60,9 & \multirow{2}{*}{61,9} \\
\hline Spesimen 3 & 59,5 & 71,6 & 59,7 & 63,6 & \\
\hline
\end{tabular}


6. Lost foam invesment casting Semen Merah $8 \%$

Berdasarkan hasil pengujian kekerasan vickres (HV) Lost foam invesment casting dengan variasi Semen Merah 8\%,

Tanah Liat 67\%, dan Air 25\% didapatkan data berikut:

Nilai Kekerasan (HV) Lost foam invesment casting Variasi Semen Merah 8\%

\begin{tabular}{|c|c|c|c|c|c|}
\hline \multirow{2}{*}{$\begin{array}{l}\text { Lost Foam Invesment } \\
\text { Semen Merah } 8 \%\end{array}$} & \multicolumn{3}{|c|}{ Titik Uji } & \multirow{2}{*}{$\begin{array}{l}\text { Rata-rata } \\
\text { spesimen }\end{array}$} & \multirow{2}{*}{$\begin{array}{c}\text { Rata-rata } \\
\text { Total }\end{array}$} \\
\hline & 1 & 2 & 3 & & \\
\hline Spesimen 1 & 65,4 & 45,5 & 63,4 & 59,4 & \multirow{3}{*}{56,9} \\
\hline Spesimen 2 & 58,5 & 56,5 & 57,1 & 57,3 & \\
\hline Spesimen 3 & 56,8 & 53,1 & 52 & 53,9 & \\
\hline
\end{tabular}

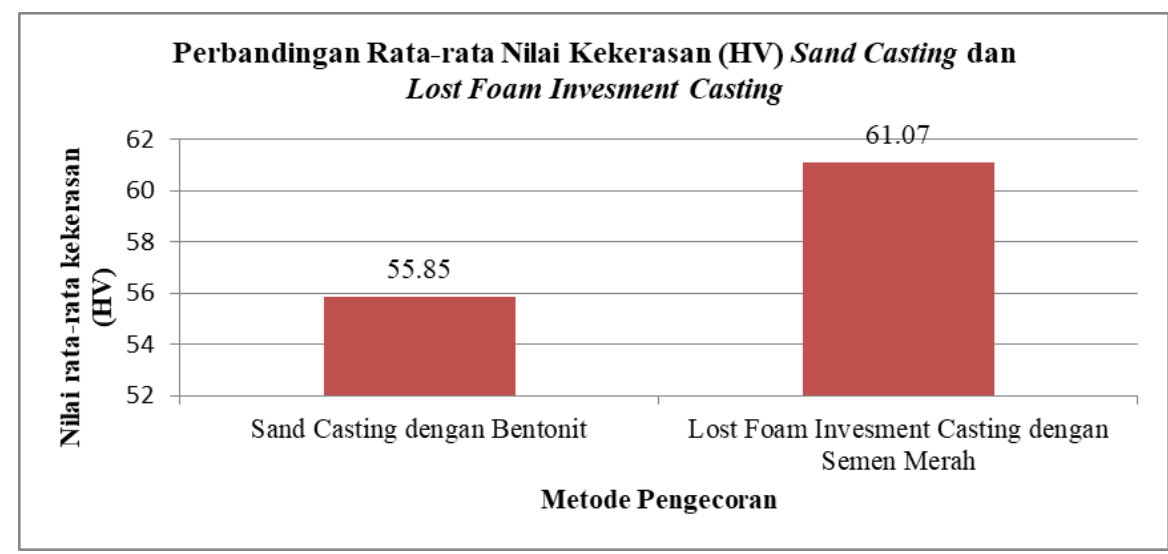

Perbandingan Nilai Kekerasan rata-rata Sand Casting dan Lost Foam Invesment Casting.

Dari hasil yang ada menunjukkan bahwa lost foam invesment casting memiliki nilai rata-rata kekerasan yang lebih tinggi dibandingkan dengan sand casting. Menurut Wibowo (2013) hal tersebut dikarenakan kecepatan pendinginan. Dimana secara teoritis pengecoran dengan die casting lebih cepat lanju pendinginannya dari sand casting.

\section{Uji Struktur Mikro}

Struktur mikro sand casting dan lost foam invesment casting pengikat $4 \%$

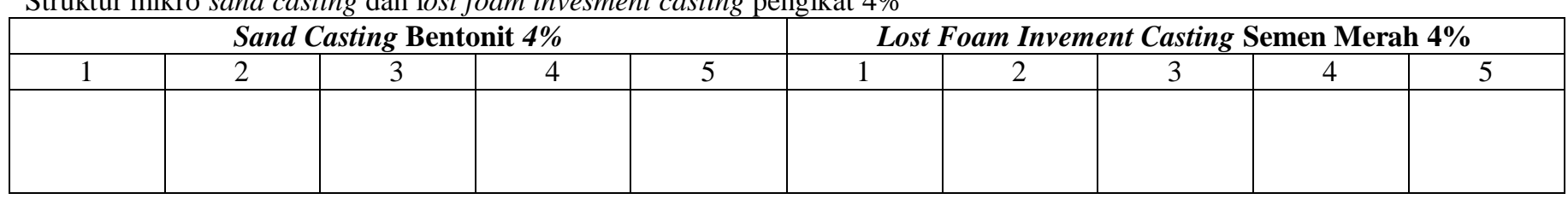

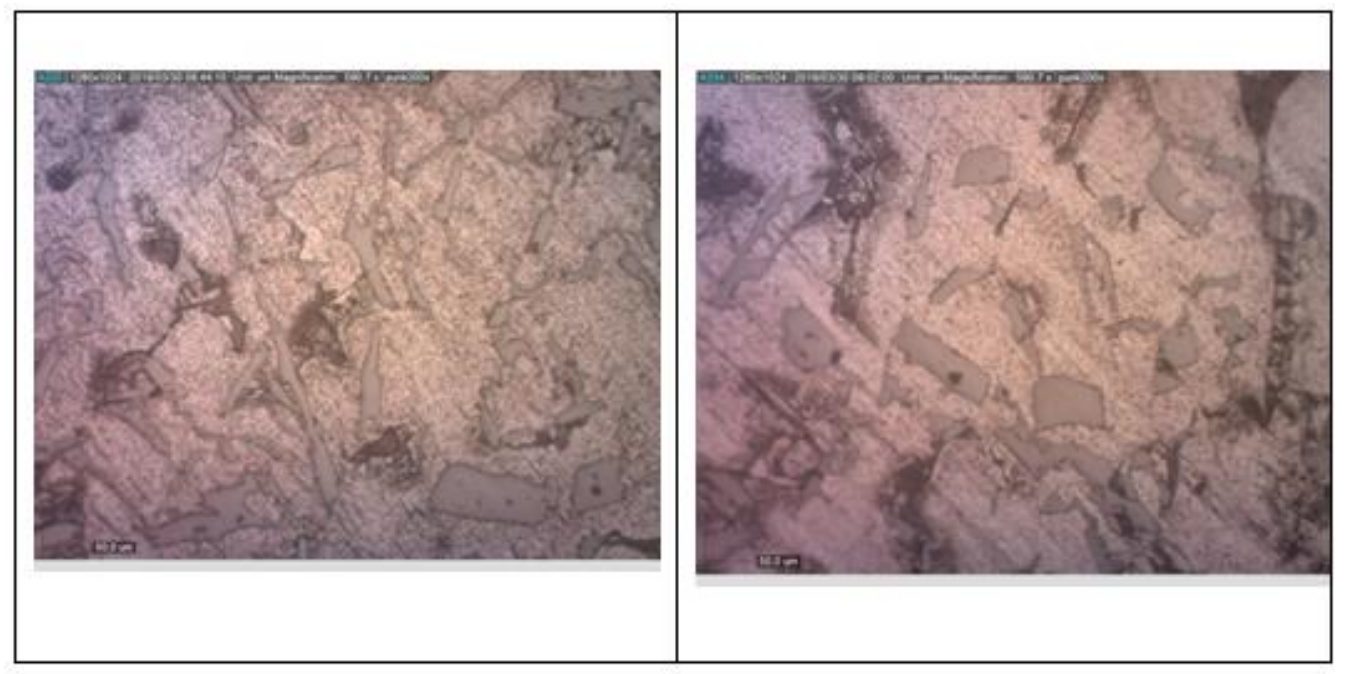


Struktur mikro sand casting dan lost foam invesment casting pengikat $6 \%$

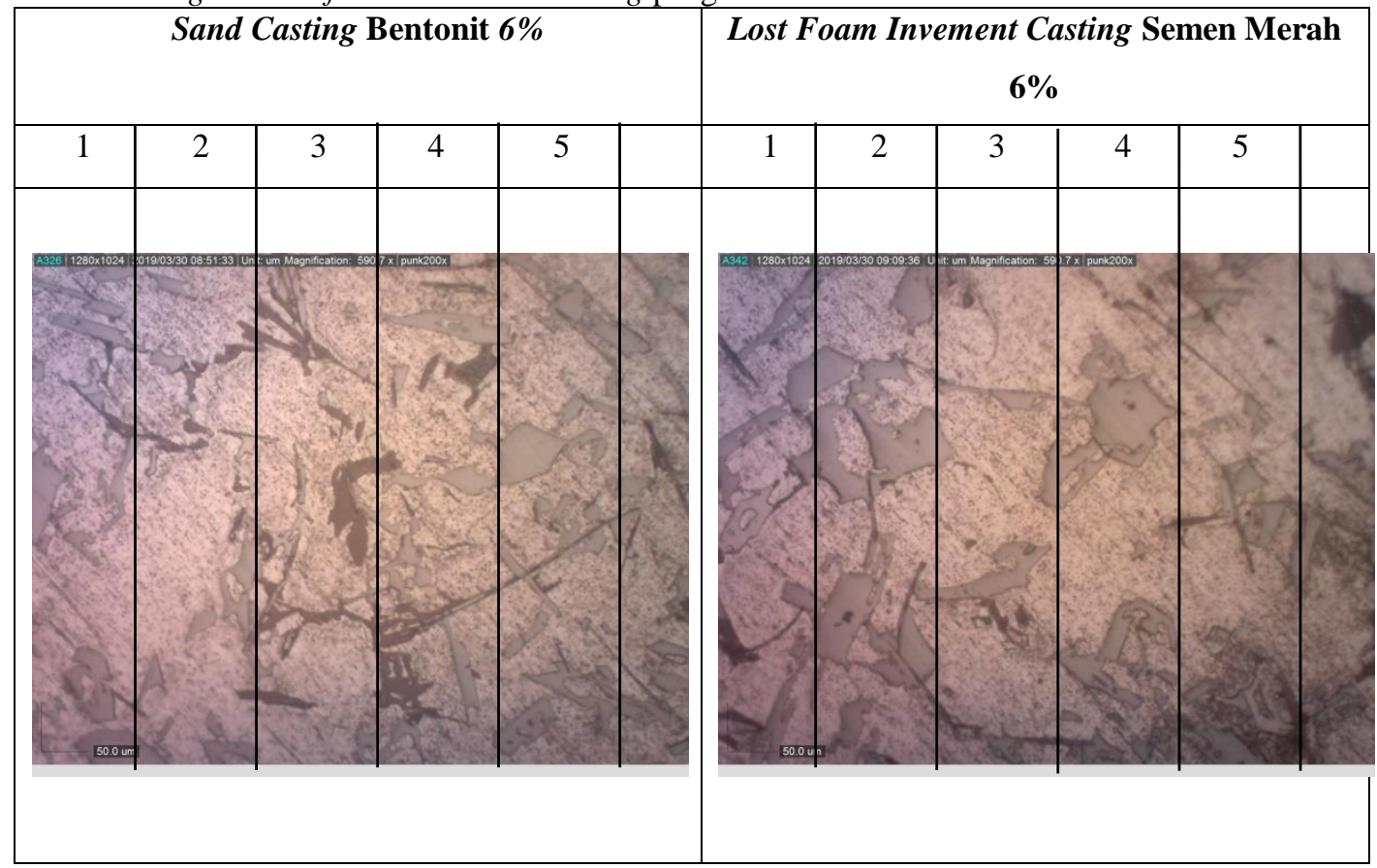

Struktur mikro sand casting dan lost foam invesment casting pengikat $8 \%$

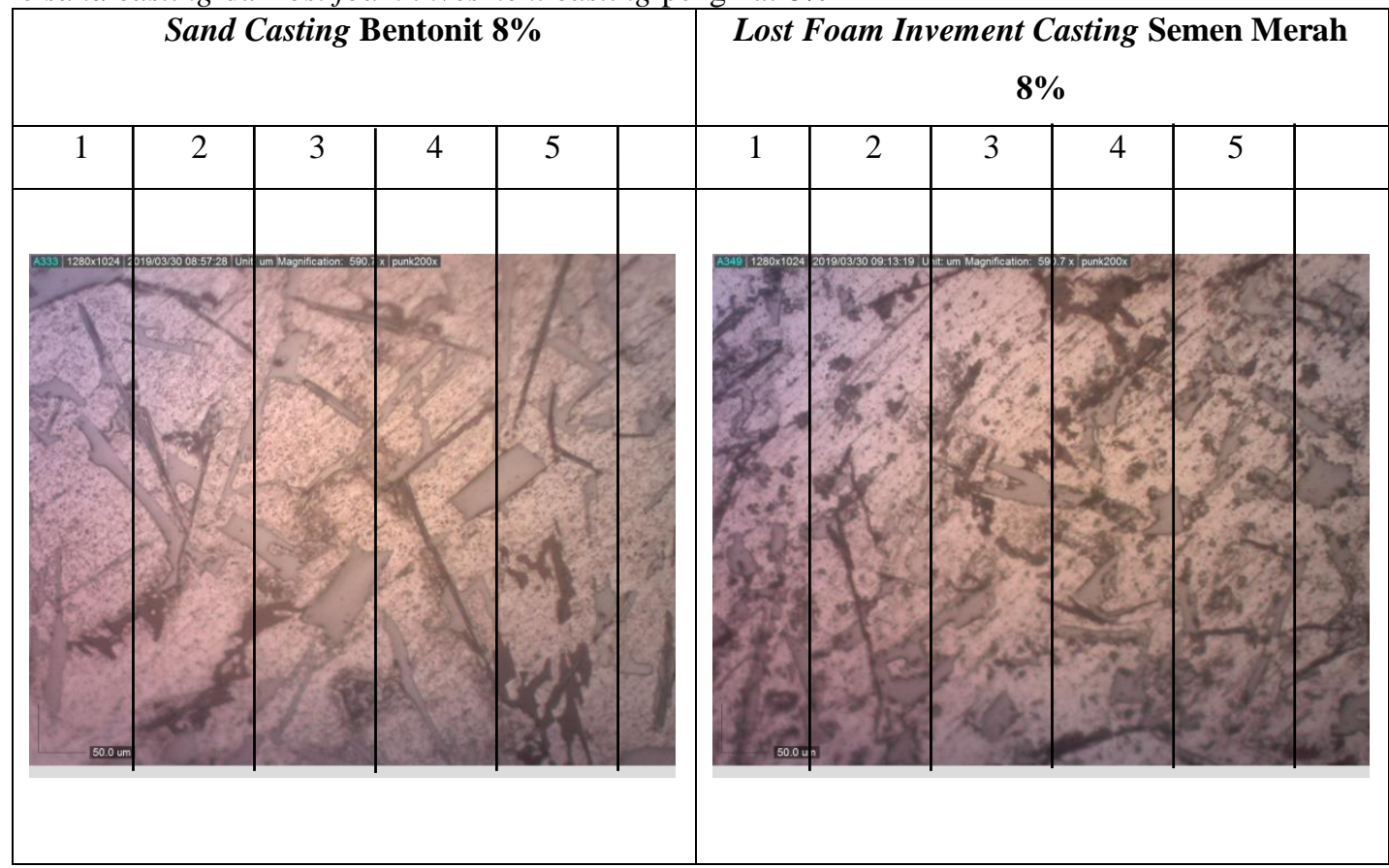

Berdasarkan data diatas terllihat secara keseluruhan struktur mikro lost foam investment casting memiliki persebaran silikon yang lebih merata. Berdasarkan penelitiann (Siagian, 2017:305) dalam penelitiann pengaruh permeabilitas cetakan dan penambahan silikon pada logam cair aluminium silikon menerangkan bahwa penambahan unsur silikon pada logam cair akan meningkatkan nilai kekerasan suatu logam. 


\section{Simpulan}

\section{PENUTUP}

Dari beberapa pengamatan yang dilakukan dapat disimpulkan secara keseluruhan pengujian didapatkan bahwa pengecoran Lost Foam Invesmet Casting memiliki kualitas hasil pengecoran yang lebih baik jika dibandingkan dengan Sand casting yang ditinjau berdasarkan komparasi pengujian visual, komparasi uji kekerasan dan komparasi uji struktur mikro pengecoran.

Berdasarkan analisis komparasi hasil pengecoran Sand Casting memiliki nilai rata-rata kekerasan 55.85 HV dan Lost Foam Invesment Casting sebesar $61.07 \mathrm{HV}$. Dari data tersebut menunjukkan bahwa secara teoritis pengecoran Lost Foam Invesment Casting memiliki nilai kekerasan rata-rata yang lebih baik. Dan Berdasarkan analisis komparasi struktur mikro antara Sand Casting variasi bentonit 4\%, bentonit 6\%, dan bentonit 8\% dengan Lost Foam Invesment Casting variasi semen merah 4\%, semen merah 6\%, dan semen merah 8\% menunjukkan secara struktur mikro metode Lost Foam Invesment Casting terlihat memiliki kekerasan yang lebih baik. Hal tersebut ditinjau dari persebaran silikon yang lebih merata, kehomogenan struktur, dan tingkat porositas logam.Dari keseluruhan point kesimpulan diatas dapat disimpulkan ada hubungan korelasi antara cacat secara visual dengan nilai kekerasan dan struktur mikro. Adapun dari hasil yang didapat secara teoritis cacat visual yang rendah menghasilkan nilai kekerasan yang lebih tinggi dan juga persebaran silikon yang lebih merata. Sehingga secara keseluruhan metode Lost Foam Invesment Casting memiliki kualitas hasil pengecoran yang lebih baik. Dan dapat dikembangkan sebagai metode pengecoran.

\section{Saran}

Setelah diuraian kesimpulan yang telah dijelaskan dan berdasarkan tujuan dari penelitiann ini maka saran yang dapat membangun pada penelitiann ini antara lain:

1. Bagi Industri Pengecoran, metode pengecoran Lost Foam Invesment Casting dapat menjadi alternative metode pengecoran selain metode pengecoran yang telah ada.

2. Bagi penelitiann dibidang pengecoran, metode Lost Foam Invesment Casting dapat dijadikan kajian penelitiann lebih lanjut. Dan sumber referensi penelitiann.

3. Bagi pengembangan ilmu logam. Lost Foam Invesment Casting dapat menjadi referensi tambahan sebagai pengembangan metode pengecoran.

Bagi penelitiann selanjutnya maka perlu dilakukan kajian yang berkaitan dengan studi rancangan cetakan yang efisien. Meliputi sistem saluran dan sistem saluran udara guna meningkatkan kualitas hasil pengecoran yang sudah ada pada metode Lost Foam Invesment Casting.

\section{DAFTAR RUJUKAN}

BPS. 2018. Pertumbuhan Produksi Manufaktur Triwulan I 2018.

Abdullah, H. 2005. Pemanfaatan Silica Fuse dan Colloidal Silica Local Untuk Pembuatan Cetakan Keramik Pada Proses Invesment Casting. Metal Indonesia.

Sugiyono. 2018. Metode Penelitiann Kuantitatif Kualitatif dan R\&D. Bandung. Alfabeta.

Suyitno, S. 2016. Aplikasi Cetakan Permanen untuk Meningkatkan Produksi dan Kualitas Produk IKM Pengecoran Logam Kuningan di Ngawen Sidokarto, Godean, Yogyakarta.

Siagian, S.J. 2017. Pengaruh Permeabilitas Cetakan Pasir dan Penambahan Silikon (Si) pada Proses Pengecoran Terhadap Kekerasan, Porositas dan Struktur Mikro Aluminium Silikon (Al-Si). 